\title{
BMJ Open How do we deal with multiple goals for care within an individual patient trajectory? A document content analysis of health service research papers on goals for care
}

\author{
G K R Berntsen, ${ }^{1,2}$ D Gammon, ${ }^{1,3}$ A Steinsbekk, ${ }^{4}$ A Salamonsen, ${ }^{2}$ N Foss, ${ }^{2}$ \\ C Ruland, ${ }^{3,5}$ V Fønnebø ${ }^{2}$
}

To cite: Berntsen GKR, Gammon D, Steinsbekk A, et al. How do we deal with multiple goals for care within an individual patient trajectory? A document content analysis of health service research papers on goals for care. BMJ Open 2015;5: 009403.

doi:10.1136/bmjopen-2015009403

- Prepublication history and additional material is available. To view please visit the journal (http://dx.doi.org/ 10.1136/bmjopen-2015009403)

Received 15 July 2015 Revised 20 October 2015 Accepted 13 November 2015

CrossMark

For numbered affiliations see end of article.

Correspondence to Dr GKR Berntsen; gro.berntsen@telemed.no

\section{ABSTRACT}

Objectives: Patients with complex long-term needs experience multiple parallel care processes, which may have conflicting or competing goals, within their individual patient trajectory (iPT). The alignment of multiple goals is often implicit or non-existent, and has received little attention in the literature. Research questions: (1) What goals for care relevant for the iPT can be identified from the literature? (2) What goal typology can be proposed based on goal

characteristics? (3) How can professionals negotiate a consistent set of goals for the iPT?

Design: Document content analysis of health service research papers, on the topic of 'goals for care'.

Setting: With the increasing prevalence of multimorbidity, guidance regarding the identification and alignment of goals for care across organisations and disciplines is urgently needed.

Participants: 70 papers that describe 'goals for care', 'health' or 'the good healthcare process' relevant to a general iPT, identified in a step-wise structured search of MEDLINE, Web of Science and Google Scholar.

Results: We developed a goal typology with four categories. Three categories are professionally defined: (1) Functional, (2) Biological/Disease and (3) Adaptive goals. The fourth category is the patient's personally defined goals. Professional and personal goals may conflict, in which case goal prioritisation by creation of a goal hierarchy can be useful. We argue that the patient has the moral and legal right to determine the goals at the top of such a goal hierarchy. Professionals can then translate personal goals into realistic professional goals such as standardised health outcomes linked to evidence-based guidelines. Thereby, when goals are aligned with one another, the iPT will be truly patient centred, while care follows professional guidelines.

Conclusions: Personal goals direct professional goals and define the success criteria of the iPT. However, making personal goals count requires brave and widesweeping attitudinal, organisational and regulatory transformation of care delivery.
Strengths and limitations of this study

- Multiple care processes within the individual patient trajectory (iPT) are often guided by implicit and possibly conflicting goals for care.

- Goal conflict within the IPT has received scant attention. With the use of 'Goal hierarchies' we show that when personal goals are set above professional goals, this may clarify and resolve tension between potentially conflicting goals.

- Reflecting on how professionals ought to engage with patients in vulnerable situations about their personal goals is a topic in its own right, but lies outside the scope of this paper.

- We identified potential goals from the health service research literature, but as no formal set of keywords define this topic we may have missed papers that could have met our inclusion criteria.

- This paper work is mainly theoretical. Further research should test the usefulness of a goal hierarchy in care for patients with complex longterm needs.

\section{INTRODUCTION}

The individual patient trajectory (iPT) for persons with multiple long-term conditions (LTCs) consists of multiple parallel care processes. ${ }^{1}$ Ideally, the iPT for a patient with multimorbidity is guided by the patient's priorities and an alignment of all professionally driven care processes and their goals. However, in an increasingly fragmented and specialised healthcare system, each specialist tends to take responsibility for only one care process. In addition, patients and informal caregivers contribute to the care process according to personal goals, which may or may not be aligned with professional goals. ${ }^{2}$ As goals for care are often implicit, patients 
with multiple LTCs at best experience a confusing iPT due to many unaligned goals for care. At worst, the iPT might grind to a deadlock between hidden, unclear overwhelming and conflicting goals. ${ }^{2-4}$

\section{Understanding the problem is half of the answer}

The following pseudonymised case story, published with patient consent by Berntsen $e t a l,{ }^{3}$ is but one in a larger case series of patients with multiple LTCs, all displaying the same deep system disconnects. 'Alfred', a 75-year-old widower, suffers from five potentially life-threatening conditions: generalised atherosclerosis including an aortal aneurysm, atrial fibrillation, congestive heart failure, renal failure and recurrent duodenal ulcers. 'Alfred' had 34 separate encounters with the healthcare services (general practitioner (GP) visits, outpatient visits and hospital admissions) the past year, including 98 days in hospital for four emergency admissions. Figure 1 outlines the health services involved in his care and their focus.

In our interview with him, 'Alfred' expressed appreciation for the care he had received, but had two main concerns:

- Transport: 'Alfred' became a widower 3 years ago, but has recently found a lady friend whom he wishes to visit. However, 'Alfred' has lost his driver's license due to health issues and public transport is unavailable. No one has addressed 'Alfred's' need for disabled transport.

- Medications: 'Alfred' said, "I take 20 tablets a day. I don't understand what they are all good for. (...) If I am not careful, 15 or 30 min after I take them, I will either vomit or have diarrhoea." This happens every 2nd to 3rd day. The medical records at the hospital or GP does not mention this problem.

'Alfred' is surrounded by specialist, nursing services and a GP working towards the common goal of improving 'Alfred's' overall health. However, they are addressing his intertwined problems through parallel series of consultations where each service limits their focus to their area of expertise and their professional standardised goals. None of the specialists have a dialogue with each other about 'Alfred's' health issues. 'Alfred's' two personal goals: to be able to visit his sweetheart and to solve the digestion problems which disrupt his medication regime, are effectively ignored. His providers tailor his care neither to his multimorbidity nor to his personal preferences. The key questions are: Which overarching goals should have guided the overall process of 'Alfred's' care, and who gets to prioritise between them?

\section{Previous research on goal setting in care processes}

The general goal of care is according to the WHO "to promote, restore or maintain health. ${ }^{5}$ Consequently, the operationalisation of the 'health' concept by each contributor to an iPT is fundamental to goal setting in healthcare. A rich literature outlines the variations in the concept of health across individuals, professions, organisations and culture. ${ }^{6}$ Essays, editorials or individual opinions ${ }^{8}{ }^{9}$ have articulated these variations, but they neglect to address how these influence the goalsetting practices of everyday care in an iPT-context. Tensions between the perspectives of healthcare professionals have been reported describing disagreement

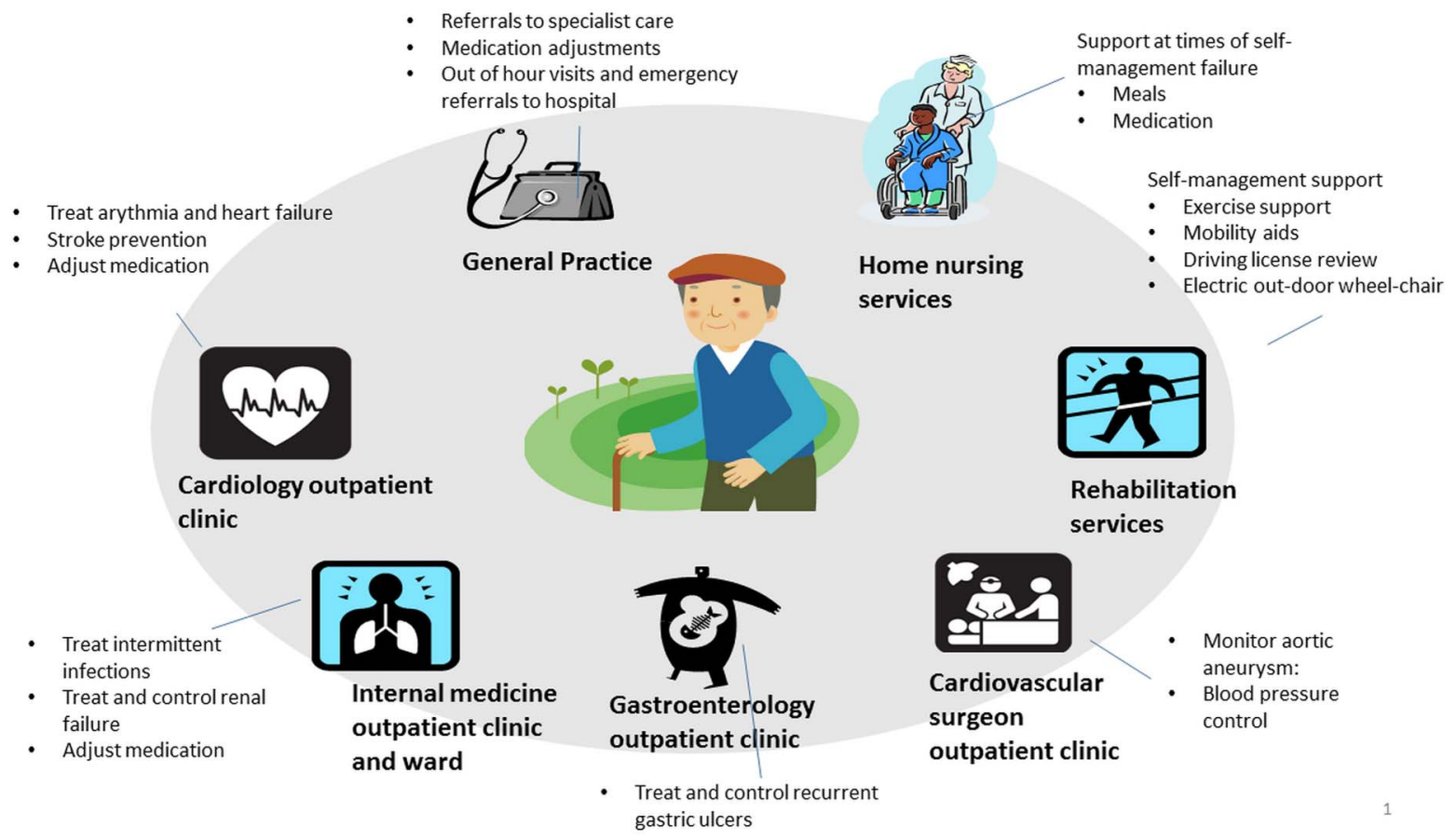

Figure 1 The health services involved in 'Alfred's' individual patient trajecotory (iPT) and the main focus of care according to the electronic medical record at the hospital and with the general practitioner, Tromsø Norway, 2012. 
both within the professional context, and between patients and professionals regarding the choice of goals. ${ }^{10-16}$ Why these goals come to differ or contradict each other has not been explored, and none of these publications discuss how these tensions can be resolved in the context of an iPT.

There is an urgent need for health professionals to understand the variation in the nature of goals for care and the process of goal setting within the context of an iPT. We have found no other studies that examine this subject. The explicit research questions of this study are:

- What goals for care relevant for the iPT can be identified from the literature?

- What typology of goals can be proposed based on goal attributes?

- How can professionals negotiate a consistent set of goals for the iPT?

\section{METHODS AND MATERIAL \\ Material}

This is a document content analysis of selected health service research papers, according to methods described by Prior, ${ }^{17} 18$ Krippendorf and Tjora. ${ }^{19} 20$ The health service research literature is the most important knowledge base for healthcare professionals in Western countries, and the key arena for professional discussion regarding what the goals of care are or ought to be. These documents provide the basis for our interpretative analysis of the health researcher's views of what healthcare's goals are or should be.

Individualised care goals are operationalisations of the general goal: "to promote, restore or maintain health". Included documents, hereafter called 'goal papers', were therefore articles in scientific journals that describe 'goals for care', 'health' or 'the good healthcare process' relevant to the general iPT as seen from the perspective of one or more roles/disciplines involved in the iPT. Papers relevant only for episodes of care or specific types of iPTs (ie, a narrow condition specific iPT) were excluded. There is no cross-disciplinary set of 'key words' that uniformly identify 'goal papers'. For example, medical ethicists discuss goals of care in terms of 'beneficence' and 'autonomy', while the medical field uses terms like 'outcomes' and 'quality'. We defined goals described by similar goal terminology as separate 'goal concepts'. Our aim was not to perform exhaustive searches to flush out all goal concepts or even all papers within a concept. Rather we aim to identify a broad set of examples of distinct goal concepts that form the basis for development of a goal typology. We, therefore, devised our own step-wise iterative search strategy, where we identified as many different distinct goal concepts as possible until additional searches no longer contributed to our ongoing goal-typology analysis (saturation).

The first author, who is a physician and health service researcher and is the guarantor of the study, performed all the literature searches. The coauthors represent a multiprofessional background (medicine, psychology, nursing, electronic-health, medical sociology and medical anthropology). Some authors had considerable patient experience.

The steps of the search were:

- Three books which review the terms 'health', 'medicine' and 'disease', respectively. ${ }^{6} 721$

- A set of seminal papers defining goals for care already familiar to the authors: WHO health definitions, works of Donabedian and the Institute of medicine. $^{22-25}$

- Systematic searches performed in 2013-2014 in MEDLINE and Web of Science (ISI), which cover most health discipline journals, ${ }^{26}$ on the terms 'concepts of health', 'goals for care/health' and 'quality of care' and limited to English language, reviews and 'health service research'.

- A snowballing process: When additional goal concepts were identified, we made supplementary searches in Google Scholar, MEDLINE and/or Web of Science to uncover more papers describing it. Searches ended when we had enough material to make a description of the essential characteristics and typical examples of goals linked to the goal concept. These searches continued until manuscript submission in 2015.

We included 70 'Goal papers', (see online supplementary appendix A) of which 34 focused on the goals for care, 17 focused on the process of care and 19 focused on both. The first paper is from 1927, but more than half are published from 2000-2012. The authors of these papers represent either WHO or locations with a predominant Western cultural background (North America, Australia and Europe).

\section{Analyses}

The included papers were subjected to stepwise deductive-inductive content analysis using Nvivo software (V.10, from QSR). All authors contributed to and commented on analyses to ensure the development of meaningful categories across professional boundaries. We developed a two-level analysis:

Identifying goal concepts: The unstructured papers were coded to reflect the underlying goal terminology, using the paper's own vocabulary. ${ }^{19}{ }_{20}$ We applied no theoretical framework at this stage. We contrasted and compared the identified codes so that all papers sharing the same terminology were grouped together, thereby identifying a goal concept. A goal concept guide, (see online supplementary appendix B) described a goal's' defining feature, the typical goals and examples of references, ensured coding consistency across papers.

Developing a goal typology and goal relationships: The following theoretical lenses were applied to the goal concepts identified in the first-level analysis:

- Disablement model: Based on Verbrugge and Jette's disablement model we created a goal typology which we applied to our set of goal concepts. ${ }^{27-29}$ 
- The ethics of authenticity, ${ }^{30}$ and specifically Taylor's work describes the emphasis that Western culture places on the person. ${ }^{31}$ With reference to this framework, we grouped goal concepts in terms of how well they accommodate the patient's personalised goal setting in the iPT.

- Goal theory was used to create a model for goal alignment within the iPT. ${ }^{32-34}$

\section{Ethics and authors' roles}

All authors helped formulate the original research questions. The work progressed in iterative collaborative cycles between the first author and coauthors. All authors had full access to included papers and coauthors were iteratively provided with both written and oral presentation of coding and analytical results as these were developed regarding goal typology, identification of relevant theoretical frameworks and the analytic results of their application. Coauthors then provided feedback in terms of insights and critical review in bilateral discussions, workshops and written feedback. All authors have read and approved the final manuscript.

We comply with the Equator network's recommendation of 'Standards for reporting Qualitative research' developed by O'Brien. ${ }^{35}$ Data did not include sensitive material. Ethics or data privacy approvals were, therefore, unnecessary.

\section{RESULTS}

What goals for care that are relevant for the iPT can be identified from the literature?

We developed a set of 14 concepts of goals for healthcare in our first-level analysis, each defined by a common terminology. For each concept, we made a statement that describes the goal concept by use of the goal's affiliated goal terminology (see box 1 and online supplementary appendix B).

\section{What typology of goals can be proposed based on goal attributes? \\ Goal framework l-based on disablement model}

The disablement model views 'Functional ability' as an overarching goal that is supported by Disease/Biological and Adaptive measures as shown in figure 2. ${ }^{27-29} 3637 \mathrm{~A}$ negative development in these domains and their goals, produce disability, while strengthening supports function and ability. Inspired by the disability framework we classified goals into the following groups:

- Functional goals: Health is a resource for a desired functional ability in a social context (Goals 6-12), and the goal of care is to restore function. Goals range from biological functions (ie, urinary continence) at one end, to highly personalised skills (ie, mountain climbing) that define a person's identity at the other end.

- Biological goals: Health is absence of biological malfunction or disease (Goals 1-5). Diseases have a
Box 1 Concepts of goals for care identified in first-level coding

1. Health is balance and homeostasis
2. Biomedical health
3. Health is to achieve desired health outcomes
4. Health is disease prevention
5. Biopsychosocial health
6. Health is freedom from disability
7. Health is a resource for well-being
8. Health is a resource for everyday life
9. Health is a resource for self-care
10. Health is a resource for autonomy
11. Health is a resource for personhood
12. Health is a resource for spirituality
13. Health is socially constructed
14. Health is determined by supernatural powers. This view is in
direct contradiction to modern healthcare foundations which
assumes that human interventions affect health. Excluded
from further analyses

biological basis or aetiology for symptomatology and signs. The goal for care is to remove the cause of disease and relieve symptoms through biological manipulation.

- Social Adaptive goals: Health is a social construct (Goal 13, from box 1). Social goals reduce the impact of a health condition, and prevent or create opportunities for health through social action. These goals can be further subdivided into goals to enhance 'Adaptive personal coping skills' and goals that create an 'Adaptive environment'.

With the exception of the papers on the disablement model (Goal 6), we found that authors neither discuss nor try to envision how they would position their goal relative to other goals. Most authors focus on isolated care goals and processes that lie firmly within their professional domain, giving little occasion to recognise or discuss a potential 'clash' with other goals in an iPT.

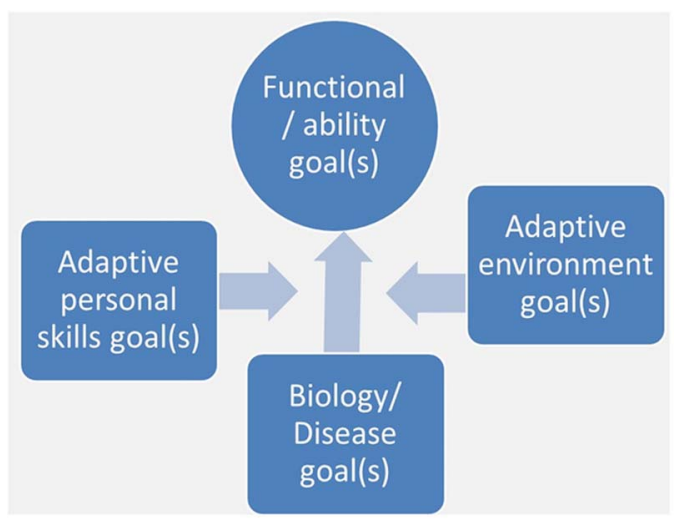

Figure 2 Goal framework I, inspired by Verbrugge and Jette. $^{27-29}$ 
Goal framework II—based on the ethics of authenticity

Although the Goal framework I incorporates all relevant goal concepts of box 1, it does not really accommodate the essence of the three 'person-centered' goal concepts (Goals 10-12). Western culture places a strong emphasis on the person and the person's duty, and the right to exercise his/her free-will to create a 'life project' for one's self. Individuals build and communicate their identities through words and actions that reflect their current values and commitments. ${ }^{38}$ Although the individual is considered the author of his/her identity, identity is developed in a social context which shapes and sets boundaries to individual pursuits. An identity is in constant development, contingent on dialogue, interactions and reactions to who he/she is. Ignoring the individuality of the person, depersonalisation, is experienced as deeply hurtful. ${ }^{38}$ Through the lens of authenticity ethics, we established two new goal groups:

1. The patient's personal goals: honour the patient's right to make decisions about his/her personal matters, which include health matters. The 'autonomy', 'personhood' and 'spirituality' goals (goals 10-12) belong here. These amount to a personal construction of what 'health' means to the individual and healthcare's role is to support them as far as realistically possible.

2. The professional goals: are the remaining goals from box 1, defined and set by professionals in terms of Function, Biology and Adaptive goals (Goals 1-9 and 13).

We have now set the patient's 'personal goals' apart from the 'functional' goals, but otherwise Goalframework $I$ is unchanged. To understand how "personal' goals can be grafted onto this framework it is necessary to examine these personally and professionally set goals closer.

\section{The tension between personal and professional goals}

Professionals are highly specialised in solving a relatively narrow set of biological or functional problems. Most professionals are not at all prepared to solve the fluctuating broad personal goals linked to a 'life project', as a professional by definition focuses on a limited set of problems. Specialisation requires a grouping of similar 'problems' (ie, patients with similar diagnoses). All problems within a 'group' share the same essential attributes. A diagnosis, such as appendicitis, represents a group of patients with the same condition. All members of the 'appendicitis' group share the same cause for disease and will benefit from the same set of interventions.

The professional mode of operation is thus strongly 'depersonalised' in the sense that professionals gain experience, test and develop their knowledge and tools in the context of groups of people. In order to identify the correct course of action, a professional's primary task is to place the patient in the correct group. Once the professional has classified the patient's problem, the specialist can draw on a wealth of knowledge from past and current patients, from personal experience and the experience of other specialists that applies to the group in question. The bottom line is that health professionals regularly treat individuals as representatives of a 'group'. Any professional who fails to aim for professionally set goals could face legal prosecution. It follows that it is in the professional's self-interest to satisfy 'professional' requirements.

\section{The pain of being ignored as a person}

Thus, it happens that patients who are already experiencing vulnerability in terms of bad health may, in addition, experience the pain of 'disappearing' as persons with a unique identity. The institutionalised trappings of healthcare treats them as an anonymous representative of a group of patients. The most extreme examples of this tension comes from palliative care, where professionals feel compelled to promote professionally set goals even when it is acknowledged that the patient is dying and further treatment is in contradiction with the patient's written 'living will'. ${ }^{39}$ The traumatising effects of depersonalisation has been well described by many patients. ${ }^{24}$

\section{The alignment of multiple goals - general goal theory}

It seems intuitively difficult to respect both professionalism and personal goals at the same time, but goal-setting theory shows how a consistent set of goals are created. Goals represent the desired future state of affairs. These serve to direct resources towards activities that support the desired state, and away from irrelevant activities. ${ }^{34}$ Both in case of conflicting goals or complementary goals that compete for resources, an explicit prioritisation of goals is called for. ${ }^{32-34}$ This is performed by creating a goal hierarchy, where the highest level goal invokes a vision of the desired future, which is then broken down into subgoals and tasks. ${ }^{32}{ }^{33}$ We have previously argued that professional skills and knowledge pertain to groups. Thus, only the individual can provide a legitimate 'vision' for the future desired state for the individual. We propose that personal goals legitimise which professional goals to pursue, and how to pursue them. This is a value-based choice sustained by the ethics of authenticity described above and by:

-Western legislation: Human rights declaration and national legislations support the individual's right to make their personal choices count in all aspects of life, including health.

- Ethics: The balance between 'paternalistic beneficence' and 'patient autonomy' challenges health personnel with two moral duties: "The first is to respect the self-determination or autonomy of the patient. The second, often neglected duty, is to help restore that autonomy or help establish it when it is absent." 4041

- Effectiveness studies. There is evidence that patient involvement and engagement in care, that is, care 
where the patient's own priorities are heeded, have better health and functional outcomes. ${ }^{42} 43$

By putting the patient's personal goals on top of the goal hierarchy, the tension between personal and professional goals effectively disappears. Professional goals are the Lego blocks that build the iPT in accordance with personal goals. The tension between personal and professional goals surfaces only when personal goals are held equal or subordinate to professional goals. The resulting goal framework is depicted in figure 3 .

\section{DISCUSSION}

Main findings

Based on document analysis of 70 health service research papers on health concepts and goals for care, we created a goal typology and goal hierarchy relevant for the iPT. The individual's personal goals are at the top of the goal hierarchy. Health professionals can then translate personal goals into realistic professional goals within Functional, Biological and Adaptive domains. Such a goal hierarchy clarifies the relationships between personal and professional goals. Goal attainment at the personal level both defines and guides successful care.

\section{Strengths and limitations}

Strengths: We have not found other papers that examine and analyse the variation of goals for care across relevant disciplines and its implications in an iPT context. Thus, this appears to be an original contribution to the discussion of how to achieve continuity of care, high-quality care and personalised care. Our multiprofessional background was vital to both identifying and understanding the epistemological and professional implications of differing goals across professional and lay roles, and the trustworthiness of our analysis.

Limitations: We may have missed papers that could have met our inclusion criteria. As the first author, who has a medical background, performed all literature searches, there may be clusters of relevant papers in

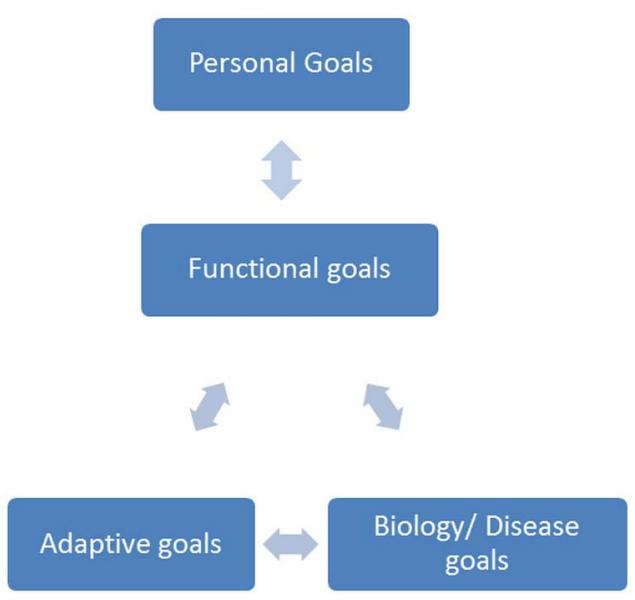

Figure 3 Goal framework II-The personalised hiearchical healthcare goal model. other domains that were missed. However, our aim was not an exhaustive search for all possible goals for care, but rather a large enough sample of goal papers that could serve as a basis for the development of a goal typology. Our goal typology seems robust, as publications identified late in the search process did not bring new goal types, indicating a saturation of the material.

Our results makes the exploration of personal goals mandatory, a practice that may be especially difficult for patients in a vulnerable situation. However, the challenges of this task, including the involvement of family and/or informal caregivers in the goal-setting process, are topics in their own right, which lie outside the scope of this paper.

The exclusion of goal 14, which holds that health is caused and maintained by supernatural or religious forces, could be viewed as a limitation. This is perhaps the oldest health model in human history. Typical interventions would appeal to higher religious or supernatural forces via institutions mostly found outside of healthcare systems. While we recognise its legitimate existence, we position our analysis to be useful within a healthcare context, which is why we excluded this goal from further analyses.

\section{Previous research}

The person-centred care literature has long underlined the importance of the patient's personal goals in all care decisions. ${ }^{44}{ }^{45}$ A goal-oriented approach, where goals are set by the patient, was proposed already in 1968 and was recently revisited by Reuben. ${ }^{45-47}$ However, the person-centred care movement has failed to merge the strengths of disease-centred and person-centred care practices. Understanding the relationships between personal and professional goals, where personal goals are the overarching guide to the setting of professional goals, is key to the delivery of truly personalised care.

Of the many interventions directed at better service coordination, neither integrated care, case management nor clinical pathways pay much attention to personal goals or goal alignment. ${ }^{48-51}$ The Chronic Care Model does emphasise 'the informed active patient', but does not really extend this into goal-oriented care. ${ }^{52}$ However, exciting examples do exist where personal goals are used to guide service coordination. The health and social services partnership in Scotland explicitly uses the formulation of desired personal outcomes as a tool for both service integration and ensuring value for the service user. ${ }^{53} 54$

\section{Implications for practice}

In 1927, Peabody had berated his colleagues for losing sight of the patient's personal needs. ${ }^{55}$ Although the call for personalised care has only grown, it still seems out of reach in modern healthcare. ${ }^{12456}$ In the light of our findings this is not surprising, since the tensions between personalised and professional goals are inherent to professionalism and specialisation, and are still 
poorly understood. The care system is currently designed to deliver single disease episodic care that supports professional goals. ${ }^{1}$ Specialists presently get no benefit from changing their scope and goals from a relatively tidy professional focus, which may be challenging and complex enough in and by itself, to encompass the fuzzy, unspecific, cross-disciplinary personal goals of patients. Turning care processes around so that professionals truly start with and adhere to personal goals will require wide sweeping, brave and visionary efforts on the part of health managers.

While this paper underlines the importance of personal goals for care, this paper is not an argument for a unilateral patient command over healthcare decisions and resources. The operationalisation of goals of care must take place in a shared decision-making process, where the professional duty is to translate the personal goals into realistic professional goals aligned with clinical, financial, ethical and regulatory boundaries. ${ }^{44} 57$ Situations where professional goals and means are incompatible with the personal goals will remain a dilemma. ${ }^{58}$ However, a goal hierarchy may be an appropriate tool to identify and discuss openly and nonjudgmentally the clashes of interest that occur when patients find that professional advice is in contradiction to their wishes.

The goal hierarchy depends heavily on an appropriate identification of personal goals. However, learning and understanding what is important to another human being is not a 'check-box' activity. Health personnel routinely experience situations that are too urgent, patients who are too ill, too cognitively impaired, too emotionally upset or feel too uninformed to make confident judgments about their goals. We have not touched on the challenges of engaging patients in a sensitive manner about their goals when these barriers occur. This is a huge and important topic in its own right, which has been reviewed and examined by many other authors. ${ }^{44} 5960$ However, even though we realise that personal goals might not be available to guide care at all times, we argue that health professionals are well taught regarding which professional goals to move towards first in such unclear situations. The challenge is perhaps the opposite: as soon as the emergency is over, in the transition from acute care to follow-up care, patients must be actively engaged in reassessing professionally set goals.

\section{Implications for future research}

Many issues emerge from the findings in this study. There is a need to test whether goal concepts, which were not included here, could have changed our analytic results. Scholars from other cultural contexts are invited to reflect on the validity of our goal hierarchy. How goal-setting practices vary with respect to professional background and care context is yet largely unexplored in the research literature. This is a theoretical piece of work, and the proposed goal-setting model needs testing in real care settings to assess if better alignment between personalised goals and professional goals improves continuity and quality of care across professional and organisational borders.

This model of goal setting does not solve the delicate and difficult issue of gaining insight into "what is important' for the individual patient. Nor does it relieve professionals of the duty of translating 'what is important' into professional goals that are realistic. It does, however, give professionals a clear and unambiguous guide to the primary goal for care: to improve and maintain health, where health is defined by 'what is important to the patient'. Personalized goals are not just 'nice to have', they are at the very core of what health care is about. Care should be evaluated in terms of meeting the personal goals set by patients. Making personal goals set the course for care, and can be likened to a paradigmatic shift that requires brave wide-sweeping regulatory, organizational and attitudinal reformation within our care systems.

\section{Author affiliations}

${ }^{1}$ Norwegian Centre for Integrated Care and Telemedicine, University Hospital of North Norway, Tromsø, Norway

${ }^{2}$ Department of Community Medicine, The National Research Center in Complementary and Alternative Medicine, UiT The Arctic University of Norway, Tromsø, Norway

${ }^{3}$ Center for Shared Decision Making and Collaborative Care Research, Oslo University Hospital, Oslo, Norway

${ }^{4}$ Department of Public Health and General Practice, Norwegian University of Science and Technology, Trondheim, Norway

${ }^{5}$ Institute of Clinical Medicine, University of Oslo, Oslo, Norway

Acknowledgements The authors are grateful to the Norwegian Research Council and Regional health authorities, Northern Norway, for their financial support.

Contributors GKRB, VF, DG, CR and AS secured support and the funding for data collection and analyses. GKRB is responsible for data collection, primary analyses and first draft of the manuscript. All authors developed the initial research question. All authors had full access to the data and provided input in terms of relevant additional papers, critical review of drafts and methodology and contributions to the final manuscript. All authors read, edited and approved the final manuscript.

Funding This study was supported by research grants from the Regional health authorities, Northern Norway (grant \# HST1024-11 5396), and the Norwegian research council (grants \# 213973, and \# 232184).

Competing interests None declared.

Provenance and peer review Not commissioned; externally peer reviewed.

Data sharing statement No additional data are available.

Open Access This is an Open Access article distributed in accordance with the Creative Commons Attribution Non Commercial (CC BY-NC 4.0) license, which permits others to distribute, remix, adapt, build upon this work noncommercially, and license their derivative works on different terms, provided the original work is properly cited and the use is non-commercial. See: http:// creativecommons.org/licenses/by-nc/4.0/

\section{REFERENCES}

1. Tinetti ME, Fried T, Boyd C. Designing health care for the most common chronic condition-multimorbidity. JAMA 2012;307:2493-4.

2. Cassel EJ. The nature of suffering and the goals of medicine. N Engl J Med 1982;306:639-45.

3. Berntsen G, Høyem A, Gammon D. The health service seen from a patient perspective. [Prosjektrapport-Helsetjenesten sett fra 
pasientens ståsted. Pasientforløp ved langvarige og komplekse behov i Troms- og Ofoten] 2014;07-2014

4. Frank AW. The wounded storyteller: body, illness, and ethics. 2nd edn. University of Chicago Press, Kindle Edition, 2013.

5. Chan M. Everybody's business : strengthening health systems to improve health outcomes : WHO's framework for action. Geneva, Switzerland, World Health Organization, 2007:1-44.

6. Blaxter M. Chapter 1 How is health defined? Health. Cambridge, UK: Polity, 2004.

7. Schei E. What is medicine? [Hva er medisin?]. Oslo, Norway, Universitetsforlaget, 2007:107-132.

8. Brown CR. Where are the patients in the quality of health care? Int $J$ Qual Health Care 2007;19:125-6.

9. Donabedian A. The quality of medical care: a concept in search of a definition. J Fam Pract 1979;9:277-84.

10. Wolf A, Ekman I, Dellenborg L. Everyday practices at the medical ward: a 16-month ethnographic field study. BMC Health Serv Res 2012;12:184.

11. Paul Olson TJ, Brasel KJ, Redmann AJ, et al. Surgeon-reported conflict with intensivists about postoperative goals of care. JAMA Surg 2013;148:29-35.

12. Ainsworth CR, Pamplin JC, Allen DA, et al. A bedside communication tool did not improve the alignment of a multidisciplinary team's goals for intensive care unit patients. J Crit Care 2013;28:112.e7-13.

13. Playford ED, Dawson L, Limbert V, et al. Goal-setting in rehabilitation: report of a workshop to explore professionals' perceptions of goal-setting. Clin Rehabil 2000;14:491-6.

14. Heisler M, Vijan S, Anderson RM, et al. When do patients and their physicians agree on diabetes treatment goals and strategies, and what difference does it make? J Gen Intern Med 2003;18:893-902.

15. Rise MB, Westerlund $H$, Bjørgen D, et al. Safely cared for or empowered in mental health care? Yes, please. Int J Soc Psychiatry 2014;60:134-8

16. Kuluski K, Gill A, Naganathan G, et al. A qualitative descriptive study on the alignment of care goals between older persons with multi-morbidities, their family physicians and informal caregivers. BMC Fam Pract 2013;14:133.

17. Prior L. Researching Documents. Emergent Methods. In: Silverman D, ed. Qualitative Research. Issues of Theory, Method and Practice, 3rd edition. London, UK, SAGE Publications Ltd, 2011:111-126.

18. Prior L. Using Documents in Social Research. In: Silverman D, ed. Qualitative Research. Issues of Theory, Method and Practice, 3rd edition. London, UK, SAGE Publications Ltd, 2011:77-92.

19. Krippendorff K. Content analysis: an introduction to its methodology. SAGE Publications, 2012.

20. Tjora A. [Qualitative research methods-a practical guide] Kvalitative forskningsmetoder i praksis. 2nd edn. Oslo: Gyldendal norsk forlag AS, 2012.

21. Hudson RP. Disease and its control: the shaping of modern thought Westport, CT: Greenwood Press, Kindle edition, 1983.

22. Donabedian A. Evaluating the quality of health care. Milbank Mem Fund Q Health Soc 1966;44:166-203.

23. WHO. Preamble to the Constitution of the World Health Organization as adopted by the International Health Conference; New York, 19-22 June 1946. 1948

24. Ottawa Charter for health promotion. $1986 \mathrm{http} / / / \mathrm{www} . w h o . i n t /$ healthpromotion/conferences/previous/ottawa/en/. (accessed july 2015).

25. Committee on Quality of Health Care in America. Crossing the quality chasm: a new health system for the 21st century. Institute of Medicine-National Academy of Sciences, 2001.

26. Falagas ME, Pitsouni El, Malietzis GA, et al. Comparison of PubMed, Scopus, Web of Science, and Google Scholar: strengths and weaknesses. FASEB J 2008;22:338-42.

27. Verbrugge LM, Jette AM. The disablement process. Soc Sci Med 1994;38:1-14.

28. Jette AM. Toward a common language for function, disability, and health. Phys Ther 2006;86:726-34.

29. Jette AM. Physical disablement concepts for physical therapy research and practice. Phys Ther 1994;74:380-6.

30. Varga S, Guignon C. Authenticity. Stanford Encyclopedia of Philosophy, 2014

31. Taylor C. The malaise of modernity Toronto: House of Anansi Press, 1991.

32. Kruglanski AW, Shah JY, Fishbach A, et al. A theory of goal systems. Adv Exp Soc Psychol 2002;34:331-78.

33. Austin JT, Vancouver JB. Goal constructs in psychology: structure, process, and content. Psychol Bull 1996;120:338.
34. Locke EA, Latham GP. Building a practically useful theory of goal setting and task motivation: a 35-year odyssey. Am Psycholo 2002;57:705-17.

35. O'Brien BC, Harris IB, Beckman TJ, et al. Standards for reporting qualitative research: a synthesis of recommendations. Acad Med 2014;89:1245-51

36. "International classification of function, disability and health". World health organization. 2001. from http://www.who.int/classifications/icf/ en/. (accessed 14 july 2015).

37. Üstün TB. "Towards a Common Language for Functioning, Disability and Health ICF. World Health Organization. 2002". Retrieved WHO/ EIP/GPE/CAS/01.3, from http://www.who.int/classifications/icf/ icfbeginnersguide.pdf?ua $=1$.

38. Taylor C. The Malaise of Modernity. Toronto, House of Anansi Press, 1991:1-135.

39. Bomba PA, Kemp M, Black JS. POLST: an improvement over traditional advance directives. Cleve Clin J Med 2012;79:457-64.

40. Pellegrino ED, Thomasma DC. The conflict between autonomy and beneficence in medical ethics: proposal for a resolution. $J$ Contemp Health Law Policy 1987;3:23-46.

41. Beauchamp T, Childress J. Respect for autonomy. Principles of biomedical ethics,. 7th edn, New York Oxford, Oxford University Press, 2013.

42. Coulter A, Ellins J. Effectiveness of strategies for informing, educating, and involving patients. BMJ 2007;335:24-7.

43. Coulter A, Entwistle Vikki A, Eccles A, et al. Personalised care planning for adults with chronic or long-term health conditions. Cochrane Database Syst Rev 2015;3:CD010523. http://onlinelibrary. wiley.com/doi/10.1002/14651858.CD010523.pub2/abstract; http:// onlinelibrary.wiley.com/store/10.1002/14651858.CD010523.pub2/ asset/CD010523.pdf ?v=1\&t=i6vx6uov\&s=f09a794e00d38f0edd6 edff92e85d45bdd0e5f65 http://dx.doi.org/10.1002/14651858. CD010523.pub2

44. Mead N, Bower P. Patient-centredness: a conceptual framework and review of the empirical literature. Soc Sci Med 2000;51: 1087-110.

45. Reuben DB, Tinetti ME. Goal-oriented patient care-an alternative health outcomes paradigm. N Engl J Med 2012;366:777-9.

46. Kiresuk T, Sherman R. Goal attainment scaling: a general method for evaluating comprehensive community mental health programs. Community Ment Health J 1968;4:443-53.

47. Mold JW, Blake GH, Becker LA. Goal-oriented medical care. Fam Med 1991;23:46-51.

48. Johri M, Beland F, Bergman $\mathrm{H}$. International experiments in integrated care for the elderly: a synthesis of the evidence. Int $J$ Geriatr Psychiatry 2003;18:222-35.

49. Reilly S, Hughes J, Challis D. Case management for long-term conditions: implementation and processes. Ageing Soc 2010;30:125-55.

50. Yarmo Roberts D. Reconceptualizing case management in theory and practice: a frontline perspective. Health Serv Manage Res 2002;15:147-64.

51. Vanhaecht $\mathrm{K}$, Panella M, Van Zelm R, et al. An overview on the history and concept of care pathways as complex interventions. Int J Care Pathw 2010;14:117-23.

52. Wagner EH, Austin BT, VonKorff M. Organizing care for patients with chronic illness. Milbank Q 1996;74:511-44.

53. Petch A, Cook A, Mlller E. Partnership working and outcomes: do health and social care partnerships deliver for users and carers? Health Soc Care Community 2013;21:623-33.

54. Miller E, Whoriskey M, Cook A. Outcomes for users and carers in the context of health and social care partnership working: from research to practice. $J$ Integr Care 2008;16:21-8.

55. Peabody FW. Landmark article March 19, 1927: the care of the patient. By Francis W. Peabody. JAMA 1984;252:813-18.

56. Engel GL. The need for a new medical model: a challenge for biomedicine. Science 1977;196:129-36.

57. Elwyn G, Edwards A, Kinnersley P, et al. Shared decision making and the concept of equipoise: the competences of involving patients in healthcare choices. Br J Gen Pract 2000;50: 892-9.

58. Starr J, Zawacki BE. Voices from the silent world of doctor and patient. Camb Q Healthc Ethics 1999;8:129-38.

59. Saha S, Beach MC, Cooper LA. Patient centeredness, cultural competence, and healthcare quality. J Natl Med Assoc 2008;100:1275-85.

60. Tilson $\mathrm{HH}$. Adherence or compliance? Changes in terminology. Ann Pharmacother 2004;38:161-2. 